\title{
Spark assisted chemical engraving (SACE) in microfactory
}

\author{
R Wüthrich ${ }^{1}$, K Fujisaki ${ }^{1}$, Ph Couthy ${ }^{2}$, L A Hof ${ }^{3}$ and H Bleuler ${ }^{1}$ \\ ${ }^{1}$ Ecole Polytechnique Fédérale de Lausanne, Laboratoire de systèmes robotiques, \\ CH-1015 Lausanne, Switzerland \\ ${ }^{2}$ Ecole Polytechnique Fédérale de Lausanne, Institut d'optique appliquée, \\ CH-1015 Lausanne, Switzerland \\ ${ }^{3}$ Delft University of Technology, Advanced Mechatronics, Mekelweg 2, 2628 CD Delft, \\ The Netherlands \\ E-mail: Rolf.Wuethrich@a3.epfl.ch
}

Received 14 January 2005, in final form 19 May 2005

Published 6 September 2005

Online at stacks.iop.org/JMM/15/S276

\begin{abstract}
Spark assisted chemical engraving (SACE) is a method for 3D microstructuring of glass or other non-conductive materials with high aspect ratio and smooth surface quality. It is applicable for rapid prototyping of microfluidic devices, for MEMS interfacing and similar applications.

Typical feature size is in the hundreds of micrometres, down to a few tens of micrometres. It is a table-top technology requiring no clean rooms and no masks and with very modest space usage. It is thus well suited for microfactories. This paper gives a basic introduction to SACE and some machining examples.
\end{abstract}

(Some figures in this article are in colour only in the electronic version)

\section{Introduction}

One of the key activities to be done in a microfactory is machining. As of today, there are still only a very few structuring methods which are compatible with the small space requirements of a microfactory. One of these methods, to be presented here, is spark assisted chemical engraving $\left(\mathrm{SACE}^{4}\right)$ for non-conductive materials, resembling in certain ways electric discharge machining [1]. It is even possible to combine the two machining methods in a single machine by adding wire electric discharge grinding (WEDG) on the same machine, as has been published earlier [2-5]. WEDG can then be used to shape the tool for SACE. Other methods to produce the tool on the same machine were also proposed [6, 7], where the tool is sharpened by inverting the polarity of the process electrodes.

Such machining methods combine high versatility for true 3D machining of various materials with relatively low complexity of the machining centre itself. The complete set-up has been demonstrated as a table-top system and is

\footnotetext{
4 Besides SACE, two other acronyms are mainly used in the literature: ECDM (electro chemical discharge machining) and ECSM (electro chemical spark machining). We prefer SACE in order to avoid confusion with ECM (electro
} chemical machining) and EDM (electro discharge machining). thus fully microfactory compatible. There is no requirement for additional support systems in the background and very low consumption of consumables. There are no mechanical perturbations (vibration, noise) generated either. Spilling of small quantities of liquid is preventable by relatively simple means. We therefore propose to consider SACE as a key machining method for microfactories.

Spark assisted chemical engraving (SACE) is a novel method for 3D microstructuring of glass or other nonconductive materials with high aspect ratio and smooth surface quality [1]. It is a kind of electric discharge machining (EDM) for non-conductive materials. The main difference is that the dielectric fluid of EDM is replaced by an electrolyte $(\mathrm{NaOH})$. The resulting process is a combination of spark action and chemical etching induced by the electric discharge. This chemical etching effect is the reason for smooth surface quality. There is no generation of microcracks. Aspect ratio can be up to 5 to 1 , in some cases even up to 10 to 1 . It is thus well suited for microfluidics, microreactors and similar devices. Through holes of a few hundred micrometres can be obtained in about $30 \mathrm{~s}$.

The basic principle of the method has been known since the pioneering work of Kurafuji and Suda in 1968, who reported the etching of microholes about $6 \mu \mathrm{m}$ in diameter 
Spark assisted chemical engraving (SACE) in microfactory

in glass [8]. A few sensors and devices have been reported [9-12], but, to our knowledge, no industrial production with SACE has ever been done. We have been studying and developing the process for a few years. We proposed a device with 3D motion of the working electrode, thus enabling etching of ditches and various features of more complicated structure. At the same time, the process has been investigated scientifically in order to describe the complex combination of various phenomena involved in machining with SACE. This has recently permitted us to increase repeatability and to understand the limit to resolution [13].

The basic operation of SACE is as follows: a nonconductive sample (usually glass) is dipped in an electrolytic solution (typically $\mathrm{NaOH}, 30 \%$ wt). A needle-shaped tool electrode (stainless steel, or better platinum or nickel) is positioned close to the sample (less than $25 \mu \mathrm{m}$ [14]). A counter electrode of large surface area is dipped into the electrolyte. A dc voltage of about $30 \mathrm{~V}$ is applied between tool (cathode) and counter electrode (anode).

First, electrolysis occurs, leading to a thin (about $100 \mu \mathrm{m}$ ) gas film around the tool. As soon as this hydrogen film screens the tool from the electrolyte, current breaks down and almost the whole voltage drop is across the gas film. This in turn results in electrical discharges (sparks) at the tool tip. The physical, thermal and, very important, chemical etching combine to remove material leaving no cracks or surface asperities. This process can be sustained over longer time while lowering the electrode or moving it sideways, thus creating the desired feature in the workpiece.

The table-top SACE machining installation and some machining results will now be presented while the phenomenological description of the process and its theoretical interpretation are discussed in more detail in another contribution [7].

\section{Table top machinery set-up}

\subsection{General needs}

As described in the introduction, the set-up for SACE machining is quite simple. However, in order to achieve reproducible machining many parameters have to be controlled. According to the recently published review [1] the main parameters affecting the machining performance are:

- temperature of the electrolyte,

- concentration and composition of the electrolyte,

- surface of the tool-electrode immerged in the electrolyte,

- gas film stability.

The last parameter is the dominant one. It is, to date, the most limiting factor in SACE machining as it is the most difficult to control. It influences mainly the discharge activity and therefore the heat generated for machining. The stability of the gas film itself depends on various other parameters which are at the time probably not all known or clearly identified. Some examples are tool shape, tool surface quality and material, electrolyte and wettability. Active research on the topic is going on in our work group $[13,15]$. The control of the other parameters is reasonably straightforward.

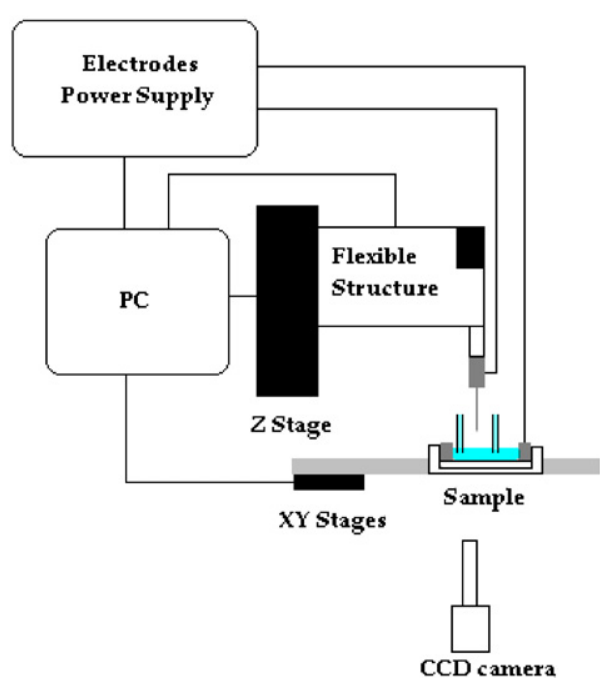

Figure 1. SACE table-top machine.

As a typical example of a desktop machinery implementing SACE technology, the last developed prototype in our research group will be presented.

\subsection{General description}

SACE machining is done on a table-top machine developed for this purpose (see figure 1). The main components are as follows:

- process cell,

- machining head,

- $X Y Z$ micrometer stage,

- vision system,

- electrode power supply,

- control hardware and software.

The process cell is mounted on an $X Y$ stage (resolution $1 \mu \mathrm{m}$, range $100 \mathrm{~mm} \times 100 \mathrm{~mm}$ ). The cell is transparent in order to give access to the vision system from below. Inside the process cell a standard $10 \mathrm{~cm}$ Pyrex ${ }^{\circledR}$ wafer, the workpiece, is fixed. In order to keep the conditions inside the electrolyte (temperature, concentration) as constant as possible, the electrolyte is injected and removed in the near vicinity of the tool-electrode (figure 2). The preferred electrolyte is $30 \%$ wt $\mathrm{NaOH}$.

Typical materials used for the electrodes are nickel, stainless steel and sometimes platinum. The manufacturing of these electrodes is described below. The head is mounted on a $Z$ stage (resolution $1 \mu \mathrm{m}$, range $50 \mathrm{~mm}$ ) and consists of a flexible structure with one degree of freedom (range $200 \mu \mathrm{m}$ ). Integrated optical sensors allow the measurement of the output relative to the mounting point of the $z$-displacement of the tool relative to the $Z$ stage. A mini voice-coil actuator can be used, if needed, to control the motion of the tool-electrode (see figure 3). This machining head can be used in several operation modes:

\section{(a) Open loop mode}

In this mode the voice coil actuator is switched off. The measurement of the optical sensor is used to determine the relative position of the tool-electrode. 


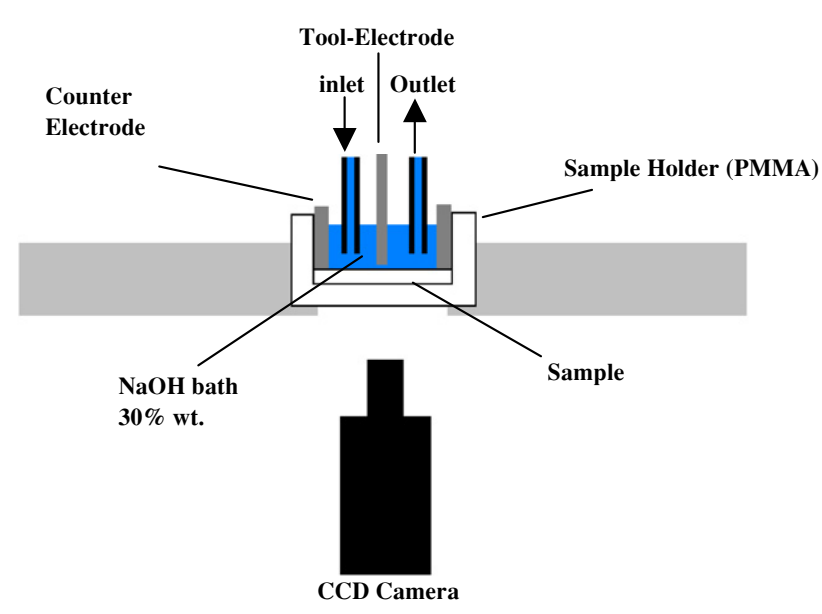

Figure 2. Schematics of the process cell.

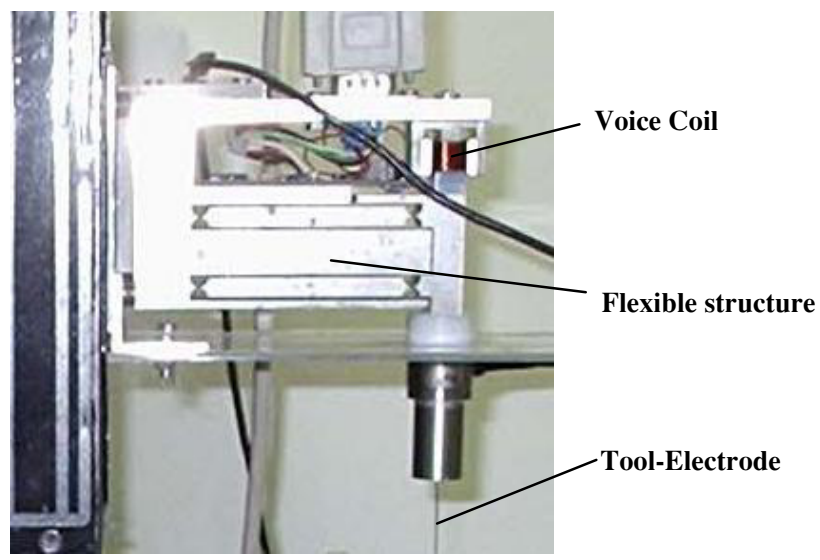

Figure 3. Machining head.

\section{(b) Closed loop mode}

In this mode the voice coil actuator is used to control the relative position of the tool-electrode according to a set point value.

As will be described below both modes are used for various purposes in this SACE desktop set-up.

The vision system consists of a CCD camera mounted below the process cell. This system is used mainly to align the tool-electrode according to already existing patterns on the Pyrex ${ }^{\circledR}$ wafer. This gives the possibility of combining SACE with clean room technologies, as already done earlier [11]. The electrode power supply is a $120 \mathrm{~W}$ dc voltage source able to maintain stable potentials up to $40 \mathrm{~V}$.

The control software is implemented in a standard PC running LabView ${ }^{\circledR}$ and MS-Windows. The software controls the power supplies of the $X Y Z$ stage and the mini voice coil of the machining head.

\subsection{Microtool manufacturing}

Manufacturing of the needed microtools is possible on the same desktop machinery. Two possibilities have been explored to date. A first possibility is to use wire electro discharge grinding (WEDG) [16]. This combination was applied first by Langen et al [2, 4, 5] and used by other research groups [3].
Another possibility of machining the tool on the same machine doing the SACE processing is proposed by Lim et al [6] who manufacture the tool-electrodes by electrochemical etching as used for STM or AFM applications. To manufacture the tool on the same machining facility as the SACE process has several advantages. The position reference is conserved and manipulations with all possible problems such as contaminations are avoided. Another advantage is the possibility of readjusting the tool if necessary (due to tool wear for example) during the machining operation [5].

\section{Potential applications}

\subsection{Fields of applications}

Applications of glass microstructuring are widespread and various. Glass has some very interesting properties such as its chemical resistance or biocompatibility. It is amorphous and therefore can be chemically machined in all directions. As glass is transparent it becomes very interesting for optical applications or applications where optical visualization of a process is needed. Some promising applications of using glass in the MEMS field are microaccelerometers, microreactors, micropumps and small medical devices (such as implantable flow sensors or drug delivery devices). Various prototypes of such devices have already been machined with SACE technology [9-12]. Within the framework of the microfactory the applications for SACE may even grow further as this technology is compatible with other process techniques and, contrary to clean room technologies, needs no ultra-clean environment or substrate.

\subsection{Machining example: array of microholes}

As a particular example for a potential application of SACE in a microfactory we discuss here the drilling of a matrix of microholes. The drilling of holes in glass is an important step in several products which may be produced by a microfactory. Holes are needed in microfluidic applications or in various sensors to provide fluid or electrical contacts for example.

3.2.1. Sample task. As a sample task a $5 \times 10$ array of precisely positioned (better than $5 \mu \mathrm{m}$ ) microholes in a Pyrex ${ }^{\circledR}$ glass wafer is described. The holes have an entering diameter of $300 \mu \mathrm{m}$ and a depth of $450 \mu \mathrm{m}$. The tool is a stainless steel microelectrode with a conical shape (cone angle: $0.78 \mathrm{rad}$ ). The used electrolyte was a $30 \%$ wt $\mathrm{NaOH}$ solution.

3.2.2. Drilling algorithm. Drilling was performed by using the open-loop mode of machining head. The algorithm for one microhole can be subdivided into three main steps (see figure 4):

1. Positioning the centre of the microhole and localization of the glass surface (calibration)

2. Drilling the microhole with SACE using gravity feed

3. Stopping SACE process when the desired depth is reached. 


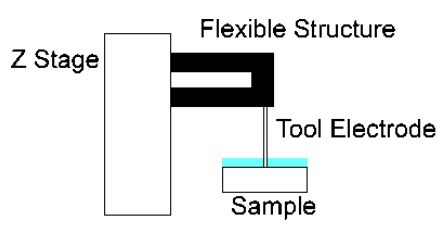

(a)

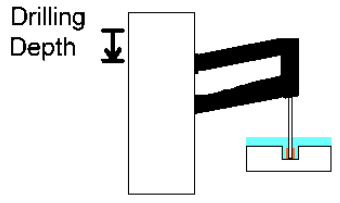

(b)

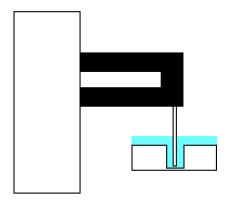

(c)

Figure 4. (a) The flexible structure remains near to the zero reference state when the tool touches the surface. (b) The depth is actuated in open loop. $(c)$ The process is stopped when the flexible structure is again in the zero reference state.

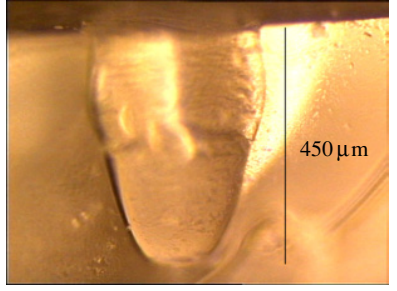

(a)

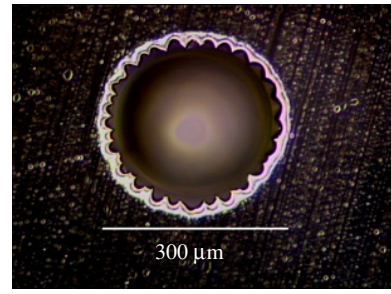

(b)

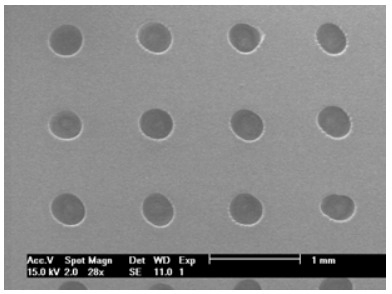

(c)

Figure 5. Microhole machined by SACE. (a) Typical profile (PDMS mold), (b) typical hole entry (viewed from above), $(c)$ matrix of micro-holes machined with $U=32 \mathrm{~V}, 30 \% \mathrm{wt}$. NaOH and machining time per hole $t=30 \mathrm{~s}$.

The positioning of the centre of the microhole is achieved using the $X Y$ stage. The localization of the glass surface is done with the machining head. Therefore the $Z$ stage moves down to the glass surface. The tool-electrode touching the glass surface deflects the flexible structure of the machining head. The precise relative position is measured with the optical sensors inside the machining head.

Once the glass surface is detected and located SACE drilling can start. Therefore a dc voltage of $32 \mathrm{~V}$ is applied. The tool-electrode moves down by gravity feed as machining is progressing. At the same time the $Z$ stage moves down too (15 $\mu \mathrm{m} \mathrm{s}^{-1}$, which is similar to the mean SACE machining speed) until reaching the desired depth of $450 \mu \mathrm{m}$.

SACE drilling is stopped by switching off the power supply as soon as the relative position between the toolelectrode and the $Z$ stage is again the same as in the glass surface localization step. In fact the process is stopped at about $440 \mu \mathrm{m}$. The last $10 \mu \mathrm{m}$ are machined even at switched off power supply.

3.2.3. Results. A hole is typically drilled in about $30 \mathrm{~s}$. A high aspect ratio, polished surface quality and microcrack free work-piece is obtained with this technique (figure 5). The hole depth average is $452 \mu \mathrm{m}$ with a variance smaller than $20 \mu \mathrm{m}$. The hole opening is relatively rough (figure $5(b)$ ) and its average diameter is $290 \mu \mathrm{m}$.

The achieved results are quite promising. A severe problem is the relatively large variance of about $20 \mu \mathrm{m}$. A closer study of the physical processes involved in SACE $[7,17,18]$ has enabled us to greatly reduce the variance [13]. This variance does not come from tool wear as one may think at first. Figures $6(a)$ and $(b)$ compare the microelectrode before machining and after 15 min machining. No significant tool wear can be observed. From these pictures it becomes clear that during the time of machining of a single microhole (about half a minute), it is not possible to get an error of $20 \mu \mathrm{m}$ because of tool wear. Indeed, as already mentioned, the main

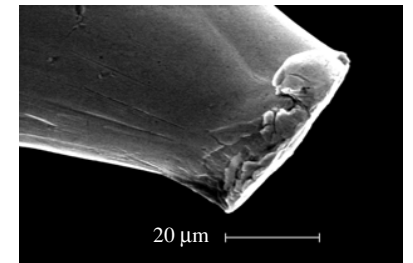

(a)

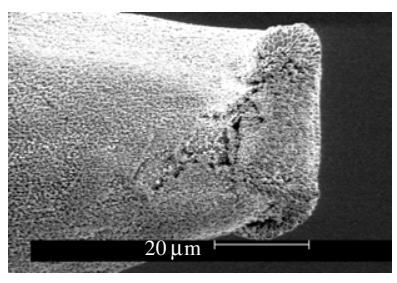

(b)
Figure 6. Micro-tool used in SACE $(a)$ before machining, $(b)$ after 15 min machining.

limiting factor is the stability of the gas film [7]. Newest results, which will be published elsewhere, show that it is possible by influencing the wettability of the tool-electrode (by adding surfactants to the electrolyte for example) to reduce this variance to below $5 \mu \mathrm{m}$ [13].

\section{Conclusion}

SACE machining is a suitable process for rapid prototyping fused silica microdevices requiring high aspect ratio, polished surface quality and microcrack free work-pieces. Typically conical hole drilling (450 $\mu \mathrm{m}$ depth, $300 \mu \mathrm{m}$ diameter) can be achieved in about $30 \mathrm{~s}$. Hole depth and diameter variance are at the moment $20 \mu \mathrm{m}$.

SACE appears, because of its simplicity and small space requirements, to be an interesting technology for microfactories. No clean environment or heavy machinery is needed.

\section{Acknowledgment}

This work was supported by the Swiss National Foundation for Research. 


\section{References}

[1] Wüthrich R and Fascio V 2005 Machining of non-conductive materials using electrochemical discharge phenomenon-an overview Int. J. Mach. Tools Manuf. 45 1095-108

[2] Langen H, Ceausoglu I, van der Meer M, Lehmann E, Bleuler $\mathrm{H}$ and Renaud $\mathrm{Ph} 1997$ Electrochemical micromachining of glass using micro-EDMed microtools Proc. Ultraprecision in Manufacturing Engineering (Braunsweig, 26-30 May) p 672

[3] Yang C T, Ho S S and Yan B H 2001 Micro hole machining of borosilicate glass trough electrochemical discharge machining (ECDM) Key Eng. Mater. 196 149-66

[4] Langen H, Fascio V, Wüthrich R and Viquerat D 2002 Three-dimensional structuring of pyrex glass devices - trajectory control Int. Conf. European Society for Precision Engineering and Nanotechnology (EUSPEN) (Eindhoven) vol 2 pp 435-8

[5] Langen H, Fascio V, Wüthrich R, Ejiri T and Viquerat D 2002 Development of desktop machinery for three-dimensional microstructuring of pyrex glass devices Int. Workshop on Microfactories (Minneapolis, USA) pp 53-6

[6] Lim H-J, Lim Y M, Kim S H and Kwak Y K 2001 Self-aligned micro tool and electrochemical discharge machining (ECDM) for ceramic materials Proc. SPIE 4416 348-53

[7] Wüthrich R, Hof L A, Lal A, Fujisaki K, Bleuler H, Mandin Ph and Picard G Physical principles and miniaturization of spark assisted chemical engraving (SACE) J. Micromech. Microeng. 15 S268-75

[8] Kurafuji H and Suda K 1968 Electrical discharge drilling of glass Ann. CIRP 16 415-9
[9] Guérin L J, Dubochet O, Zeberli J F, Clot P and Renaud Ph 1998 Miniature one-shot valve Micro Electro Mechanical Systems_IEEE 11th Annual Int. Workshop Proc. pp 425-8

[10] Esashi M, Matsumoto Y and Shoji S 1990 Absolute pressure sensors by air-tight electrical feedthrough structure Sensors Actuators A 21-23 1048-52

[11] Daridon A, Fascio V, Lichtenberg J, Wüthrich R, Langen H, Verpoorte E and De Rooij N F 2001 Multi-layer microfluidic glass chips for microanalytical applications Fresenius J. Anal. Chem. 371 261-9

[12] Lee E S, Howard D, Liang E, Collins S D and Smith R L 2004 Removable tubing interconnects for glass-based micro-fluidic systems made using ECDM J. Micromech. Microeng. 14 535-41

[13] Wüthrich R and Hof L A 2005 The gas film in spark assisted chemical engraving (SACE) - a key element for micro-machining applications Int. J. Mach. Tools Manuf. submitted

[14] Fascio V, Wüthrich R, Viquerat D and Langen H 1999 3D microstructuring of glass using electrochemical discharge machining (ECDM) Int. Symp. on Michromechatronics and Human Science (MHS'99) pp 179-83

[15] Wüthrich R, Comninellis Ch and Bleuler H 2005 Electrochemistry under extreme current densities Electrochim. Acta at press

[16] Masuzawa T, Fujino M, Kobayashi K and Suzuki T 1985 Ann. CIRP 34431

[17] Wüthrich R and Bleuler H 2004 A model for electrode effects using percolation theory Electrochim. Acta 49 1547-54

[18] Wüthrich R, Fascio V and Bleuler H 2004 A stochastic model for electrode effects Electrochim. Acta 49 4005-10 